\title{
Interactive comment on "Assessment of extreme flows and uncertainty under climate change: disentangling the contribution of RCPs, GCMs and internal climate variability" by Chao Gao et al.
}

\section{Chao Gao et al.}

chao_gao@zju.edu.cn

Received and published: 29 April 2020

Dear Referee \#1,

We highly appreciate your review and useful suggestions for our manuscript. We provide our answers to your queries below.

Kind regards, all authors

Queries by anonymous referee \#1 RC1 \& answers by authors are as follows:

Comment \#1: Since the internal climate variability in this paper is represented by the simulations of SDRM-MCREM, whether the contribution of internal climate variability 
to the total uncertainty is directly relevant with the performances of SDRM-MCREM? For example, in Figure 10, the contribution of internal climate variability in annual maximum 1-day flow for larger return periods is obviously larger than smaller return periods, whether this indicates the poor performance of SDRM-MCREM in simulating extremes? Please explain.

Interactive

Authors' response: Thanks for your question. There are two commonly-used apcomment proaches for the quantification of the internal variability of the climate system: the first one is using multiple members of GCMs to reflect internal climate variability (Bracegirdle et al., 2014); the second one is taking the randomness of weather generators or stochastic rainfall models as the internal climate variability (Lafaysse et al., 2014; Fatichi et al., 2016). In this way, it is unavoidable that the contribution of internal climate variability is dependent on the performances of the adopted methods. This means that the contribution of internal climate variability to the total uncertainty is not only directly dependent on the performance of SDRM-MCREM in this study, but also dependent on the performance of other methods if other methods were adopted. In this study, to avoid the impacts of a poor performance of a stochastic rainfall model on its randomness and affecting the representation of internal climate variability, we have made great efforts to apply the well-performing stochastic rainfall model SDRM-MCREM, which showed good results for simulation of both rainfall time-series characteristics and rainfall event characteristics. The advantages of SDRM-MCREM compared to other weather generators and stochastic rainfall models are described in Gao et al. (2020a). In addition, the inferior performance of weather generators and stochastic rainfall models in simulating extremes and inherent large uncertainties is a common problem. Compared to other weather generators, the SDRM-MCREM performs relatively better in reproducing rainfall extremes (Gao et al. 2020a). To draw conclusions about the contributions of different uncertainty sources in a more accurate and reliable way in this study, we summarized the findings of this study for an average return period and also compared these results with previous studies (see Page 22-23, Line 431-438).

Printer-friendly version

Discussion paper 


\section{References:}

Bracegirdle, T. J., Turner, J., Hosking, J. S., and Phillips, T.: Sources of uncertainty in projections of twenty-first century westerly wind changes over the Amundsen Sea, West Antarctica, in CMIP5 climate models, Clim. Dyn., 43, 2093-2104, https://doi.org/10.1007/s00382-013-2032-1, 2014.

Lafaysse, M., Hingray, B., Mezghani, A., Gailhard, J., and Terray, L.: Internal variability and model uncertainty components in future hydrometeorological projections: The Alpine Durance basin, Water Resour. Res., 50, 3317-3341, 2014.

Fatichi, S., Ivanov, V. Y., Paschalis, A., Peleg, N., Molnar, P., Rimkus, S., Kim, J., Burlando, P., and Caporali, E.: Uncertainty partition challenges the predictability of vital details of climate change, Earth Future, 4, 240-251, https://doi.org/10.1002/2015ef000336, 2016.

Gao, C., Booij, M. J., and Xu, Y.-P.: Development and hydrometeorological evaluation of a new stochastic daily rainfall model: coupling Markov chain with rainfall event model, J. Hydrol., under revision, 2020a.

Comment \#2: Another main usage of stochastic rainfall model is to downscale climate model outputs by adjusting parameters of stochastic rainfall models for climate change impact studies. The future GCMs rainfall data in this study are directly simulated by SDRM-MCREM using the bias corrected GCM future data rather than through downscaling by SDRM-MCREM. Can the authors explain why you conducted like this?

Authors' response: There are two reasons why we conducted the study in this way. Firstly, the bias-corrected future GCM rainfall data already contain sufficient information to reflect the impacts of climate change on rainfall characteristics. Gao et al. (2020b) investigated the changes of rainfall event characteristics using bias-corrected historical and future GCM data, and found that not only the distributions of rainfall duration and rainfall depth would change, but also the temporal patterns of rainfall events

Printer-friendly version

Discussion paper 
would change in the future. Secondly, obtaining realizations of future rainfall time series through simulating the bias-corrected future GCM data using SDRM-MCREM in order to consider future internal climate variability is more straightforward and easier. As far as we know, using weather generators or stochastic rainfall models to downscale GCM future simulations currently is mainly through perturbing the parameters of weather generators, like the transition probabilities of rainfall occurrence and parameters of the distribution of rainfall amount, using monthly averaged additive or multiplicative change factors of GCM projections (Chen et al., 2012; Li and Babovic, 2018). However, it cannot be guaranteed that these kinds of downscaling methods can fully incorporate changes of rainfall characteristics (e.g. temporal patterns of rainfall events) although it has been commonly used in previous studies. In addition, it is complicated to carry out the whole downscaling process. Based on the above, it is considered more convenient and useful to directly simulate the bias-corrected GCM rainfall series using SDRM-MCREM in this study.

\section{References:}

Gao, C., Booij, M. J., and Xu, Y. P.: Impacts of climate change on characteristics of dailyâĂŘscale rainfall events based on nine selected GCMs under four CMIP5 RCP scenarios in Qu River basin, east China, Int. J. Climatol., 40, 887-907, https://doi.org/10.1002/joc.6246, 2020b.

Chen, J., Brissette, F. P., and Leconte, R.: Downscaling of weather generator parameters to quantify hydrological impacts of climate change, Climate Research, 51, 185200, https://doi.org/10.3354/cr01062, 2012.

$\mathrm{Li}$, X., and Babovic, V.: Multi-site multivariate downscaling of global climate model outputs: an integrated framework combining quantile mapping, stochastic weather generator and Empirical Copula approaches, Clim. Dyn., 52, 5775-5799, https://doi.org/10.1007/s00382-018-4480-0, 2018.

Comment \#3: Obviously, there also exists uncertainty in the process of hydrological

Printer-friendly version

Discussion paper
Interactive

comment 
modelling. Why did your study only consider the uncertainty of RCPs, GCMs and internal climate variability and neglects the uncertainty of hydrological parameters that seems can be easily incorporated. Please explain.

Authors' response: Thanks for your question. In the process of hydrological modelling, uncertainty in hydrological model structures is also present besides uncertainty in hydrological parameters. There are two reasons why we did not take the uncertainty in hydrological modelling into consideration in this study. Firstly, many previous studies indicated that uncertainty originating from climate projections is generally larger than uncertainty in the hydrological simulation process (Teng et al., 2012;Karlsson et al., 2016), and uncertainty from hydrological model structures and parameters sets is less important for peak flows (Vetter et al., 2016;De Niel et al., 2019) (See Page 2, Line 56-63). Repeating their work seems not very necessary. In addition, the main purposes of this study are (1) to use the newly-developed well-performing stochastic rainfall model SDRM-MCREM to generate multiple realizations of GCM data and reflect internal climate variability; (2) to investigate how climate projection uncertainties, including RCP uncertainty, GCM uncertainty and internal climate variability, propagate into streamflow projections and estimate their contributions to streamflow projection uncertainty. This has also been described in the introduction section (see Page 3, Line 87-95). Because of this, we did not take the uncertainty of hydrological modelling into account in this study. For future research work, to obtain a comprehensive insight into projected changes of high flows and low flows and the contributions of different uncertainty sources, it is aimed to consider all sources of uncertainty arising from scenarios, climate models, internal climate variability, downscaling methods, hydrological models and hydrological parameters (See Page 23, Line 446-448).

\section{References:}

Printer-friendly version

De Niel, J., Van Uytven, E., and Willems, P.: Uncertainty Analysis of Climate Change Impact on River Flow Extremes Based on a Large Multi-Model Ensemble, Water Resour. Manag., 33, 4319-4333, https://doi.org/10.1007/s11269-019-02370-0, 2019. 
Karlsson, I. B., Sonnenborg, T. O., Refsgaard, J. C., Trolle, D., Børgesen, C. D., Olesen, J. E., Jeppesen, E., and Jensen, K. H.: Combined effects of climate models, hydrological model structures and land use scenarios on hydrological impacts of climate change, J. Hydrol., 535, 301-317, https://doi.org/10.1016/j.jhydrol.2016.01.069, 2016.

Teng, J., Vaze, J., Chiew, F. H. S., Wang, B., and Perraud, J.-M.: Estimating the Relative Uncertainties Sourced from GCMs and Hydrological Models in Modeling Climate Change Impact on Runoff, J. Hydrometeorol., 13, 122-139, https://doi.org/10.1175/jhmd-11-058.1, 2012.

Vetter, T., Reinhardt, J., Flörke, M., van Griensven, A., Hattermann, F., Huang, S., Koch, H., Pechlivanidis, I. G., Plötner, S., Seidou, O., Su, B., Vervoort, R. W., and Krysanova, V.: Evaluation of sources of uncertainty in projected hydrological changes under climate change in 12 large-scale river basins, Clim. Change, 141, 419-433, https://doi.org/10.1007/s10584-016-1794-y, 2016.

Comment \#4: L36. "responses of" <-> "responses to".

Authors' response: Thank you. We will replace "responses of" with "responses to".

Comment \#5: L39. "the coupled system" - the atmosphere-ocean coupled system? Please make it clear.

Authors' response: Thank you. "the coupled system" does refer to "the coupled atmosphere-ocean system". We will revise it.

Comment \#6: L48. "The relative importance" refers to what? Please make it clear.

Authors' response:Thank you. Here "The relative importance" refers to the relative importance of different uncertainty sources. Therefore, the original content will be modified to "The relative importance of different uncertainty sources".

Comment \#7: L124. "In this study, we used the distribution mapping (DM) method to correct GCM-simulated climate variable" - at this point in the text, some further 
explanation about why choosing the DM method is needed in the context.

Authors' response: Thank you. We will further explain why we chose the DM method to bias correct the simulations of GCMs in this study. The contents which will be added are "Considering that the distribution mapping (DM) method usually shows a comprehensive skill in bias correcting the mean, standard deviation and various frequencybased indices and even correcting unobserved extreme values compared with other existing bias correction approaches like power transformation (PT), local intensity scaling (LOCI), linear scaling (LS), delta change (DC) and quantile mapping (QM) (Fang et al., 2015; Teutschbein and Seibert, 2012; Ji et al., 2020), the DM method was selected to correct GCM-simulated climate variables based on observations in this study."

\section{Reference:}

Fang, G. H., Yang, J., Chen, Y. N., and Zammit, C.: Comparing bias correction methods in downscaling meteorological variables for a hydrologic impact study in an arid area in China, Hydrol. Earth Syst. Sci., 19, 2547-2559, https://doi.org/10.5194/hess-19-25472015, 2015.

Teutschbein, C., and Seibert, J.: Bias correction of regional climate model simulations for hydrological climate-change impact studies: Review and evaluation of different methods, J. Hydrol., 456-457, 12-29, https://doi.org/10.1016/j.jhydrol.2012.05.052, 2012.

Ji, X., Li, Y., Luo, X., He, D., Guo, R., Wang, J., Bai, Y., Yue, C., and Liu, C.: Evaluation of bias correction methods for APHRODITE data to improve hydrologic simulation in a large Himalayan basin, Atmospheric Research, 242, https://doi.org/10.1016/j.atmosres.2020.104964, 2020.

Comment \#8: L129. Please check the correctness of Eq. (2).

Authors' response: Thank you for your comment. There is indeed a small error in Eq. (2). The variable "xsim,his" at the right hand side of the equation will be modified to 
"xsim,fut".

Comment \#9: L189. "is" <-> "was". The tense of this paper in the method part is a bit confusing. Please check the whole paper and ensure proper use of the tense.

Authors' response: Thank you. We will correct this. In addition, we have checked the tense throughout the whole manuscript and will make the corresponding corrections, especially in the description of the used methods, including the sections of methods and results.

Comment \#10: L338. In this paper, when investigating the changes of high flows and low flows, the 5-, 10- and 20-year return periods are adopted. Why not use the larger return periods such 50-year and 100-year return periods that are more useful information for assessment of extreme hydrological events?

Authors' response: To avoid introducing additional uncertainty through fitting observed and simulated 30-year high and low flows series with a probability distribution, the empirical cumulative distribution was directly used to calculate the values of high flows and low flows at different return periods in this study. Therefore, the largest return period calculated in this study is nearly 30 years, which obviously is smaller than 50 years and 100 years. This is why the high flows and low flows at 50-year and 100-year return periods are not reported in this study.

Comment \#11: L421. "account for approximately 54-60\% on average"-Does this mean the proportion of the total uncertainty? Please make it clear.

Authors' response: Thank you. This is exactly the proportion of the total uncertainty. Therefore, we will modify the original content to "account for approximately $54-60 \%$ of the total uncertainty on average".

Interactive comment on Hydrol. Earth Syst. Sci. Discuss., https://doi.org/10.5194/hess-202025, 2020. 